\title{
El Fondo Documental “Ángel Palerm y Carmen Viqueira Landa" del CIESAS
}

\author{
Ximena González Munizaga
}

$\tau$ a solicitud de donación del Fondo "Ángel Palerm y Carmen Viqueira Landa" surge de la los fundadores del Centro de Investigaciones y Estudios Superiores en Antropología Social (CIESAS), en especial con sus archivos, con el objetivo de ayudar a reconstruir y preservar la historia del Centro y del desarrollo de la antropología en México. Virginia García Acosta, directora general del ciesAs, se acercó a los herederos del doctor Palerm, Ángel y Jacinta, quienes no tuvieron inconveniente en que este valioso acervo se conservara en la institución que él fundó. En marzo de 2012 iniciaron los trámites para inventariar y trasladar el acervo de documentos, libros y revistas.

Los registros constan de textos clásicos de la antropología y de una colección de psicología. Hay aproximadamente 3000 materiales entre libros y revistas, 150 de ellos, encuadernados en piel, son de la autoría de Ángel Palerm o tesis de sus alumnos. Además del contenido especializado, la donación tiene una importancia especial para el CIESAs porque incluye el archivo personal de Palerm, primer director de la institución e impulsor de su creación, así como primeras versiones de algunos de sus escritos, fichas de trabajo de campo, sobretiros de sus artículos e información de su trayectoria académica.

El material del archivo deja ver su pensamiento político y humanista, relata su experiencia en el Partido Socialista Unificado de Cataluña y de México y su renuncia a él, así como sus experiencias como combatiente en la Guerra Civil Española. En el cuento "Desembarco", que parece más la bitácora del viaje de Ibiza a Francia, nos lleva a viajar junto a él en esa horrible travesía y la descripción de la guerra civil, con sus tanquetas, fusiles y ametralladoras, hace sentir que "cada disparo es una baja". Esos relatos, como Palerm comenta, no pretenden ser un trabajo de aspiraciones literarias, sino un mapa que, fechado en febrero de 1940 en México, permite hacer desaparecer el tiempo y el espacio y sentir que recordar es revivir.

\section{Documentary Collection "Ángel Palerm y Carmen Viqueira Landa” of CIESAS}

Ximena González Munizaga: Centro de Investigaciones y Estudios Superiores en Antropología Social, Distrito Federal, México xgmuniza@ciesas.edu.mx 


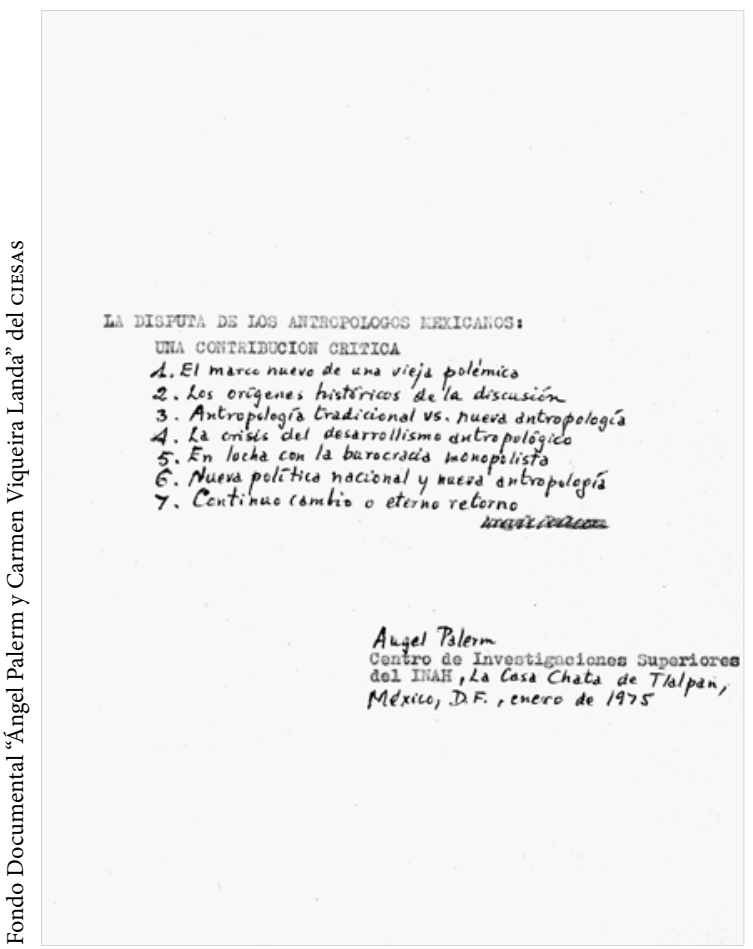

Borrador del artículo "La disputa de los antropólogos mexicanos: una contribución crítica” de Ángel Palerm, 1975.

A continuación ofrezco una selección de este rico Fondo del CIESAS:

- Borradores de los artículos que escribió, publicados por el Centro de Investigaciones Superiores del Instituto Nacional de Antropología e Historia (CIS-INAH) y por otras casas editoriales.

- Certificados de membresía de varias asociaciones científicas, como The New York Academy of Sciences y del Ateneo en Washington.

- El primer número del Boletín del Instituto de Ciencias Sociales de la Escuela de Graduados de la Universidad Iberoamericana (UIA), en el que se anuncia el nombramiento de Palerm como director y el comienzo de los trabajos de la Escuela en enero de 1967.

- El anteproyecto de plan de estudios de la licenciatura en antropología social de la División de

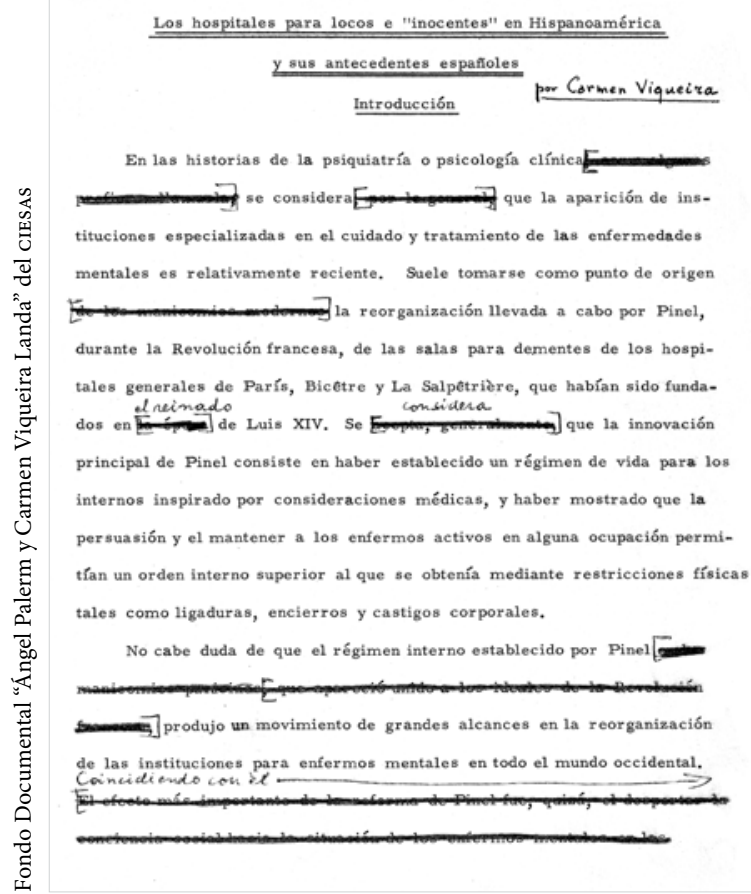

Borrador del artículo "Los hospitales para locos e 'inocentes' en Hispanoamérica y sus antecedentes españoles" de Carmen Viqueira, 1965.

Ciencias Sociales y Humanidades de la Universidad Autónoma Metropolitana (UAM).

Este hombre sistemático y ordenado inventarió y enlistó las obras que leyó durante su primer año en México, de 1939 a 1940: un total de 235 libros. También en el archivo se encuentran las entrevistas que Marisol Alonso realizó entre marzo y septiembre de 1979 en la ciudad de México, en las que habla de su vida en Ibiza, de la influencia del Partido Socialista Obrero Español (PSOE) y de su inicio en la vida política como anarcosindicalista junto a pescadores, marineros, guarnicioneros, carpinteros, peluqueros, etc. En esas entrevistas relata que a los 15 años de edad fue detenido por primera vez en Ibiza, donde lo trataron bien por ser hijo de buena familia, regañaron a sus padres y ahí acabó la cosa. Nos trae a la memoria parte de la historia de la Escuela Nacional de Antropología e Historia (ENAH) y el 
excelente cuerpo de profesores que impartía clases ahí: Martínez del Río, Caso, Kirchhoff, Bosch Gimpera, Kelly, Foster, Beals, Carrasco, Armillas y cómo, según Palerm, se avecinaba la catástrofe de esa Escuela. En este archivo personal están sus boletas de estudio y certificados, con los que puede comprobarse que siempre fue alumno de excelentes calificaciones.

Este Fondo contiene fichas de trabajo de la zona de Tajín, Veracruz (1949), y de San Marcos Ahuacatlán, Puebla (1951), diarios de campo y un test aplicado en la zona rural e indígena de Tajín a sugerencia de Carmen Viqueira, varios tests psicodiagnósticos de Rorschach aplicados a totonacos de 6 a 53 años, así como las gráficas de resultados y dibujos hechos por niños totonacos. También hay ponencias y participaciones en seminarios, encuentros y reuniones, lo mismo que informes de trabajo de su periodo como funcionario de la Organización de los Estados Americanos (OEA).

Para la historia del CIESAS es muy importante la carta fechada el 4 de diciembre de 1972, enviada a Enrique Florescano, en ese momento coordinador general del PESAH, con sus comentarios sobre el proyecto de decreto presidencial para crear un organismo dentro del INAH que probablemente se refiere al CIS-INAH, actual CIESAS. Palerm juega con propuestas de nombre: Centro, Instituto, Colegio, etc., y da sus argumentos para que sea uno u otro. Entre las funciones y responsabilidades que tendría la nueva institución, y lo primordial para él, figuraba: "la obligación de ayudar al desarrollo de la antropología y de la investigación antropológica en los centros de enseñanza superior del país" y consideraba requisito indispensable "mantener la investigación viva, a los investigadores sobre sus pies y produciendo, y también establecer una conexión más viva con la docencia profesional y con las instituciones dedicadas a ella".

Los documentos del archivo de Carmen Viqueira están contenidos en tres cajas, los de Ángel Palerm llenan entre 12 y 13 cajas. En estos documentos se

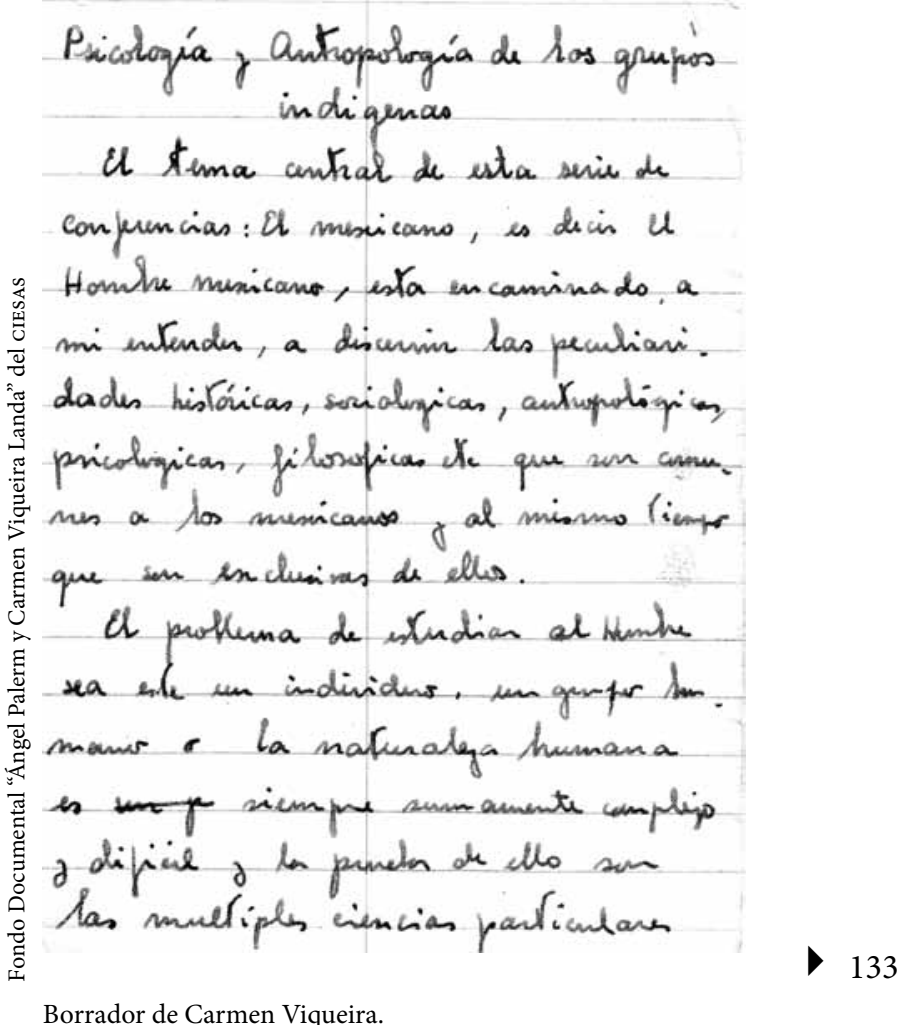

encuentran reconocimientos de la UIA por su trayectoria docente, títulos de maestría y doctorado, los manuscritos de un par de libros, primeras versiones de artículos, notas sobre algunos textos, su currículum vitae, correspondencia con editoriales y un borrador de solicitud para hacer trabajo de campo en Acolhuacan dirigido a las autoridades civiles y militares (1977). El Fondo se dividió en los subfondos "Ángel Palerm Vich" y "Carmen Viqueira Landa”, se están inventariando y organizando en secciones: "Académico", "Funcionario", "Activista político" y "Personal". Los documentos se están clasificando para que ingresen al catálogo de la base de datos en línea y para que puedan ser consultados por cualquier usuario en las instalaciones del Archivo Histórico del ciesas, ubicado en Ximilpa 39, en el Centro de Tlalpan, en la ciudad de México. 